\title{
Music effects on phonological awareness development in 3-year-old children
}

\author{
Maria Manuel Vidal ${ }^{1, *}$ (D), Marisa Lousada ${ }^{2}$ and Marina Vigário ${ }^{1}$ \\ ${ }^{1}$ Center of Linguistics, School of Arts and Humanities, University of Lisbon and ${ }^{2}$ School of Health Sciences \\ (ESSUA) and Center for Health Technology and Services Research (CINTESIS.UA), University of Aveiro \\ *Corresponding author. Emails: tf.mmvidal@gmail.com; labfon@letras.ulisboa.pt
}

(Received 03 May 2018; revised 01 November 2019; accepted 04 November 2019)

\begin{abstract}
Music and language engage similar processing mechanisms, including auditory processing and higher cognitive functions, recruiting partially overlapping brain structures. It has been argued that both are related in child development and that linguistic functions can be positively influenced by music training above 4 -years-old. In this randomized control study, with a test-training-retest methodology, 44 children (3-4 years old) were assessed with a phonological awareness test, prior and after an intervention period of a school year with weekly music classes (experimental group, $n=23$ ) or visual arts classes (control group, $n=21$ ) in kindergarten. In the preassessment there were no significant differences between groups. When comparing pre- and postassessment, results showed significant differences in both groups, but music classes' students outperformed the control group, showing larger differences between the beginning and the end of the intervention. Improvement in both groups is expected due to general developmental reasons. However, the fact that children receiving music classes show greater improvement indicates that music lessons have influenced phonological awareness. Our results support the hypothesis that music training may promote language abilities, specifically phonological awareness, prior to the ages previously studied.
\end{abstract}

Keywords: language development; music training; phonological awareness

In the last years, the relation between music and language development has attracted great attention in various research fields, and in particular in linguistics. According to Gerry, Unrau, and Trainor (2012) active music participation seems to influence child development at as soon as 6 months of age, as participating in classes with appropriate pedagogical methodologies improves social and communicative development between infants and their parents. Later in development, music training and/or music abilities have been found to predict literacy outcomes (phonological awareness [word, syllabic] and phonemic awareness, reading precursors, reading, and reading in dyslexia; Anvari, Trainor, Woodside, \& Levy, 2002; Corrigall \& reproduction in any medium, provided the original work is properly cited. 
Trainor, 2011). Phonological awareness in turn has been shown to be a predictor of subsequent literacy abilities, including reading and writing (Cardoso-Martins, 1991; Öney \& Durgunoğlu, 1997). Thus, music training may have a role to play in promoting child development and/or language rehabilitation (François, Chobert, Besson, \& Schön, 2013).

Working phonological skills as early as age 3 might be important, given that the relation between these abilities and reading disabilities is well established. Dyslexia and developmental language disorder are usually considered different disorders that co-occur frequently (Catts, Adlof, Hogan, \& Weismer, 2005). Music potential in developing phonological awareness may also help in the rehabilitation of dyslexia. Because dyslexia has a large impact on the child's academic performance and psychosocial outcome (Bishop \& Snowling, 2004; Clegg, Hollis, Mawhood, \& Rutter, 2005), and leads to difficulties at school as well as through adulthood (Lyon, 1998), it is most relevant exploring the role of music in the enhancement of language skills in dyslexic individuals as well.

Until now, most of the studies investigated this effect in children above 4 years old. In the investigation involving a test-training-retest methodology, the training period consisted most often in an intensive training. Although results from this type of research indicate significant effects of music in children's subsequent abilities, the sort of intensive training involved is difficult to provide to children at these ages in large scale, for instance, as part of the state schools curricula. The aim of the present study is to contribute to understanding the relation between music training and phonological development before the ages already studied, with typical music classes that were not specifically designed to promote phonological awareness abilities, with no intensive training, in a kindergarten context.

It is possible that language-particular features also play a part in the way music interacts with phonological awareness. In the experiment we report here, the children tested are native speakers of European Portuguese (EP), a language where the effect of music in phonological awareness promotion was never investigated, to the best of our knowledge. Some of the most salient phonological properties are given below.

EP is an intonational language, with word-level stress, massive reduction of unstressed vowels, and very frequent unstressed vowel deletion, resulting in enhanced word stress. EP shows many phonological cues to the prosodic word level, but no clear phonological evidence for the foot level; lexical syllables are rather simple, typically maximally of the form consonant-consonant-vowel-consonant (CCVC). Postlexically, the status of syllables is less clear, due to schwa deletions that may originate sequences of six consonants and more; resyllabification applies across words, within the intonational phrase; and there is sparse pitch accent distribution, with obligatory pitch accents only in intonational phrase nuclear position (Collischonn \& Wetzels, 2016; Frota, 2000, 2014; Mateus \& D’Andrade, 2000). EP thus presents a rich and specific combination of prosodic properties, and music training may help children to improve their auditory acuity and better access at least some of the prosodic information that is relevant in the language. Given its specific prosodic profile, it is possible that the impact of music training in phonologic awareness and development in EP exhibits some differences relative to other languages. Variation in the effect of music training across languages is naturally an important 
topic of research, and the present investigation is also expected to contribute to the knowledge in this area.

Music and language are related in terms of function, type of stimuli, structure (Lehrdahl \& Jackendoff, 1983), and the use of vocal apparatus at the human production level (Anvari et al., 2002). Their component elements are different, but they may require the same basic learning processes (Saffran, Johnson, Aslin \& Newport, 1999), enabling the extraction from a sequence of acoustically variable signals a small number of categories that are meaningful (Degé \& Schwarzer, 2011). Durational and pitch modifications present in language (as prosodic elements) and in music (in melody and rhythm) are used to mark group boundaries. In music processing, in order to organize sound sequences into relevant patterns, listeners use metric, rhythmic, melodic, and harmonic information-there are larger and smaller pitch and rhythmic units, organized in hierarchical structures (Krumhansl, 2000; Radocy, LeBlanc, \& Boyle, 1990). In language development, in order to segment the speech signal, the infant uses properties such as stress, prominence, and rhythm, intonation, and prosodic boundaries, which signal the significant categories and units organized in hierarchical structures (Bion, Benavides-Varela, \& Nespor, 2011; Frota, Cruz, Matos, \& Vigário, 2016).

As said above, studying music influence on phonological awareness development is of particular interest because of the potential role of the former in promoting phonological awareness and of the latter in subsequent linguistic-related abilities, such as reading and writing. Phonological awareness can be defined as the explicit awareness of the sound structure of words in oral language (Freitas, Alves, \& Costa, 2007; Herrera, Lorenzo, Defior, Fernandez-Smith, \& Costa-Giomi, 2011; Sim-Sim, 2006; Wagner et al., 1997), referring to the understanding, detection, and manipulation of a language sound system (Freitas et al., 2007; Patscheke, Degé, \& Schwarzer, 2016; Sim-Sim, 2006). This sensitivity to the sound structure of language includes the ability to analyze and manipulate language at the word level (large phonological units) and at the phoneme level (small phonological units; Patscheke et al., 2016). Phonemic awareness ability refers to the sensitivity to the sound of the smallest independently perceivable units of language: the phonemes (Herrera et al., 2011). Beyond this, there is also the intrasyllabic awareness, which refers to the ability to manipulate sound sequences larger than the phoneme, but smaller than the syllable: the syllable onset and rhyme (Afonso, 2015; Sim-Sim, 2006).

Phonological awareness is involved in tasks like isolating individual words from the speech flow (Patscheke et al., 2016); rhymes evocation (Rios, 2009; Santos, 2012), identifying words that rhyme; blending syllables; counting the syllables within a word; identifying words that have a common syllable (Lathroum, 2011); the segmentation of syllables into onset and rhyme (Alves, Castro, \& Correia, 2009; Rios, 2009); blending sounds (Lathroum, 2011); sound segmentation, elision, or matching (Yopp, 1992); correcting speech errors; or discriminating words in terms of a different sound (Lathroum, 2011). The child must recognize these linguistic sound categories in spite of variations in pitch, tempo, speaker, and context (Anvari et al., 2002). During kindergarten, children develop phonological awareness skills, although some aspects seem to be acquired informally, when comparing and discriminating words that sound similar (Lathroum, 2011). According to Lane and Pullen (2004), rhyming is one of the first skills that is acquired, and 
children are able to identify words that sound similar or different before they are able to manipulate sounds within words. Metrical rhyme implies detecting the similarities between two words from the stressed vowel or diphthong to the end of the word (Afonso, 2015). Identifying words that rhyme has been considered the easiest operation within phonological awareness tasks, emerging in children 3 to 3;5 years old, and gradually developing until children reach 5 years of age (Rios, 2009; Santos, 2012).

Mastering phonological awareness skills is of key importance in writing and reading acquisition, as transforming print symbolic information into linguistic mental representations is based on children's prior language experience, in particular, their attention to the components of words (Gordon, Fehd \& McCandliss, 2015; Wright \& Jacobs, 2003), and on their ability to recognize and manipulate the phonological segments of spoken words (Peynircioglu, Durgunoglu, \& Uney-Kusefoglu, 2002).

Neural mechanisms responsible for phonological awareness can also explain individual differences in literacy learning (Schlaggar \& McCandliss, 2007). Children's understanding of how the written symbols map onto the sounds that compose words is better when the child has fully developed phonological awareness abilities, and auditory sensitivity to the spoken phonemic units is an advantage in learning the orthographic-to-phonological mapping system, being considered a prerequisite to reading (Goswami, 1990) and a predictor of this subsequent ability (Cardoso-Martins, 1991; Öney \& Durgunoğlu, 1997).

The relation between music and phonological awareness has been studied in the last years. Experiencing and acquiring a given spoken language impacts on phonological awareness skills. For example, when comparing phonological differences between similar words to learn their meanings, the child must be able to compare sounds across words, developing phonological sensitivity over this learning process. Peynircioglu et al. (2002) claim that if this happens, some different auditory experiences may also enhance phonological awareness skills: if music and speech processing involve similar skills in sound discrimination, temporal sequencing, attention, and working memory, getting the child exposed not only to speech but also to music may help developing auditory skills that might contribute to improve speech perception and enhance phonological awareness (Lathroum, 2011). In both speech and music, children must discriminate and process sounds that are extracted from perceived acoustic signals varying over time. Auditory temporal processing, important in both areas, is key, for instance, to children's discrimination of similar-sounding consonants, which is essential in phonological awareness and the learning of reading and writing (Lathroum, 2011).

The fact that music and language share the same auditory domain, the organization of discrete perceptual elements into structured sequences (Patel, 2003), the need for segmentation of sound streams in smaller units (Lathroum, 2011), and common processing mechanisms (McMullen \& Saffran, 2004; Patel, 2008) may help to understand the relation between music and language development (Degé \& Schwarzer, 2011).

Music training may increase general auditory sensitivity that transfers to the ability to perceive phonological structure (Butzlaff, 2000; Degé \& Schwarzer, 2011; Patel, 2008, 2011). Recent research has shown that phonological awareness is related to music aptitude, and also to music training (Degé, Kubicek, \& 


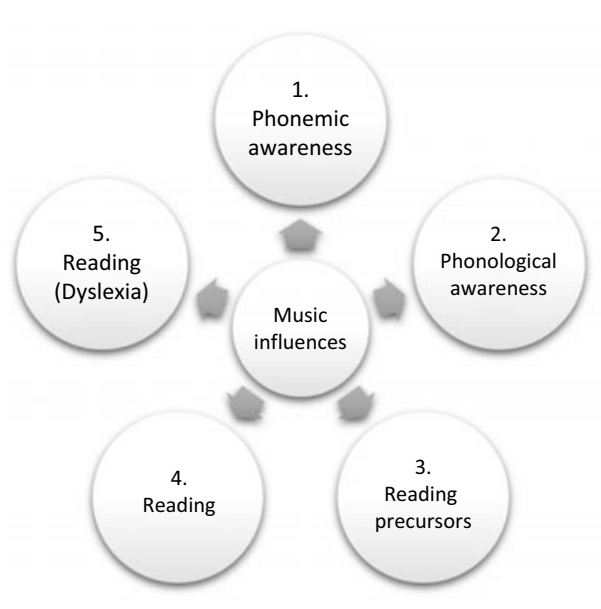

\begin{tabular}{|c|c|c|}
\hline & Ages & References \\
\hline 1. & $\begin{array}{l}3-6 \\
4: 6-5: 6 \\
4-7\end{array}$ & $\begin{array}{l}\text { Gromko (2005) } \\
\text { Lamb \& Gregory (1993) } \\
\text { Peynircioglu, Durgunoglu \& } \\
\text { Kusefoglu (2002) }\end{array}$ \\
\hline 2. & $\begin{array}{l}4-5 \\
5 \\
8 \\
5-6 \\
3-4\end{array}$ & $\begin{array}{l}\text { Anvari et al. (2002) } \\
\text { Degé \& Schwarzer (2011); } \\
\text { François et al. (2013) } \\
\text { Lathroum (2011) } \\
\text { Moritz (2007) } \\
\text { Woodroof Carr et al. (2014) }\end{array}$ \\
\hline 3. & $\begin{array}{l}4-5 \\
4 \\
6 \\
4: 6-5: 6 \\
3-4\end{array}$ & $\begin{array}{l}\text { Anvari et al. (2002) } \\
\text { Degé, Kubicek, \& Schawrzer } \\
\text { (2015) } \\
\text { Degé \& Schawrzer (2012) } \\
\text { Lamb \& Gregory (1993) } \\
\text { Woodruf Carr et al. (2014) }\end{array}$ \\
\hline 4. & $6-9$ & Zuk et al. (2013) \\
\hline 5. & $\begin{array}{l}7 \\
10\end{array}$ & $\begin{array}{l}\text { Overy (2003); } \\
\text { Forgeard, Schlaug, Norton, } \\
\text { Rosam \& Iyengar (2008) }\end{array}$ \\
\hline
\end{tabular}

Figure 1. Skills already studied about music influence in language development, with reference to the authors and the ages comprehended in each study.

Schwarzer, 2015). Besides that, a bulk of studies on the influence of musicality/ musical training in language development have shown effects of music on phonological awareness (word, syllabic, and phonemic awareness), reading precursors (which includes the first skill), reading, and reading in dyslexia, as is depicted in Figure 1. In some work, the relation between music and linguistic skills is measured without music training, by measuring individual differences in music aptitude (Anvari et al., 2002; Degé et al., 2015; Degé \& Schwarzer, 2012; Forgeard et al., 2008; Lamb \& Gregory, 1993; Lathroum, 2011; Peynircioglu et al., 2002; Rubinson, 2009; Woodruff Carr, White-Schwoch, Tierney, Strait, \& Kraus, 2014; Zuk, Andrade, Andrade, Gardiner, \& Gaab, 2013); other studies rely on a test-training-retest methodology, being closer to the demonstration of a causal relation effect (Degé \& Schwarzer, 2011; François et al., 2013; Herrera et al., 2011; Moreno et al., 2009; Moreno, Friesen, \& Bialstok, 2011).

According to Anvari et al. (2002), pitch processing is significantly positively correlated with phonological (syllabic and phonemic) awareness. Degé and Schwarzer (2012) showed positive associations between phonological (syllabic and phonemic) awareness and musical perception and reproduction skills. Lathroum (2011) also found that music perception has a significant contribution to phonological awareness, showing that, taken together, music perception, visual spatial skills, and age predict phonological awareness development. Woodruff Carr et al. (2014) studied the relation between beat synchronization and prereading skills in 3-year-olds, investigating the hypothesis that beat synchronization predicts neural speech encoding and reading readiness in American monolingual preschoolers between 3 and 4 years old. The authors found that preschoolers who can synchronize are better in prereading skills, indicating a neural network common to these tasks.

Moritz (2007) found that (a) phonological segmentation subskills, as well as rhyming ability, were significantly related to rhythm pattern production and 
discrimination abilities and (b) children with intensive music training showed disproportionate improvement in rhyming skills. In this study, musical rhythm subskills were assessed at the beginning and at the end of the school year, in a kindergarten in North America, comparing students from two different schools with different amounts of music training (Kodály daily classes versus weekly classes that were not based on Kodály's methodology).

In a meta-analysis that included 13 studies $(N=901)$ where the authors tested the direct transfer hypothesis, including music training versus control groups, pre- versus postcomparison measures, and indication that reading was held constant across groups, meaning that intervention and control groups should have equivalent amounts of reading instruction (Gordon et al., 2015). Participants in this meta-analysis were speakers of different languages belonging to distinct rhythmic classes, including EP. In this study, Gordon et al. (2015) concluded that music training leads to gains in phonological awareness; in other words, the improvement of rhyming skills tended to grow stronger with increased hours of music training. In addition, in only 5 of the included studies, music influence on reading fluency was studied, and no significant transfer effect was found for these measures. This controversial finding may be related to the fact that 2 of these studies included children with reading disabilities.

With a randomized control study, Bolduc (2009) compared children in a program specifically designed to increase preschoolers' interest in reading and writing by using musical activities with a control group with music lessons guided by the Menistére de l'Éducation du Quebec music program. The experimental group developed better phonological awareness skills when compared to the control group. In this study, Canadian children (French speakers, mean age 5 years, 1 month [5;1 years] old) had daily lessons, during $60 \mathrm{~min}$, for 15 weeks. Degé and Schwarzer (2011) concluded that children submitted to a phonological skills and a music program showed significant improvement from pre- to postassessment, in large phonological units. In this randomized control study the authors divided the sample ( 5 to 6 years old) in 3 groups that were submitted to (a) a music program, (b) a phonological awareness program, and (c) a sports training program, $10 \mathrm{~min}$, daily basis classes for 20 weeks.

Herrera et al. (2011) showed that (a) a 1st experimental group with phonological awareness training and a 2nd that associated music and phonological awareness outperformed the control group (with no training) in the rhyme task; and (b) in syllabic tapping both experimental groups outperformed the control group. The authors directed a stratified randomization procedure to understand the effects of phonological and musical training on Spanish- and Tamazight-speaking children reading readiness (mean age 4;6 years old). Training period was of 8 weeks ( $2 \mathrm{hr} /$ week classes), plus a second period of training, 6 months after the first phase, where the procedure was repeated. Herrera et al. (2011) and Patscheke et al. (2016) found the same general results, although not designing a music program specifically for promoting phonological awareness skills. In these studies, a significant increase was found in phonological awareness of large phonological units (a) in a music trained group and (b) in a phonological skills trained group, when compared with a control group with sports training. The authors examined these effects in 4- to 6-year-old children of immigrant Kurdish, Russian, Asian, and American families 
who were in Germany at least for 5 years and who reported a poor German language level. The training was implemented three times a week, in 20-min sessions, during 14 weeks.

Moreno et al. (2011) found no significant differences between the experimental group with music classes and the control group with visual arts classes, in rhyming assessment. The authors studied the effect of music training in promoting preliteracy skills in 4- to 6-year-old children, in Canadian English speakers, randomly assigned to music classes (experimental group) or visual arts classes (control group). Children had a training period of twice a day classes, during $45 \mathrm{~min}$, for a total of 40 classes. Pre- and postassessment consisted of a phonological awareness test (rhyme comprehension and production) and a visual auditory learning test. No significant differences between groups were found in the rhyming assessment.

Studies that relate music aptitude and language abilities may indicate a relationship between music and language, but they do not prove a causal relation effect. This means that potential effects of self-selection, environmental, or genetic characteristics can influence linguistics skills in people with higher music abilities (musicians or not; Gordon et al., 2015). In the randomization procedure, by contrast, children are randomly distributed to form the experimental and control groups, which is not guided by prior aptitude or motivation. For this reason, data from longitudinal randomized control studies, like the present one, with test-training-retest methods, may provide new insights into what has already been established concerning the relation between music and language on the basis of music aptitude.

In our study, we randomized the sample into an experimental group with music classes and a control group with visual arts classes, and assessed the children before and after the training period (music vs. alternative training). Our aim is to study music influence in phonological awareness at ages prior to those already investigated, specifically, in 3-year-olds. We also want to know if this influence emerges with regular music classes, in kindergartens regular days (once a week, for $45 \mathrm{~min}$ ), during a preschool year, having no specific design to promoting phonological awareness skills.

\section{Methodology}

\section{Participants}

Subject selection criteria included the following: monolingual children whose native language was EP; children aged between 3;0 and 3;11 years old; and participation in $70 \%$ of the classes (criteria used in Patscheke et al., 2016). Children with language disorder were not included in this study. Likewise, children with a history of referral to or enrollment in speech-language therapy were excluded, as well as children diagnosed with cognitive or other associated conditions. In order to control for these exclusion criteria, a questionnaire characterizing the child (first language, enrollment in speech and language therapy, and presence of sensorial, motor, or mental disorder) was completed by kindergarten teachers.

The collection of data was done in two successive school years. From the initial group of 53 children, 9 were excluded. One child was transferred to a different kindergarten, 2 children were not Portuguese native speakers, 1 child did not attend 
$70 \%$ of the classes, and 5 children were removed from the analysis because their score in the phonological awareness test was beyond $2 S D$ from the mean, being treated as outliers. Those 5 children were assessed with all the subtests applied of the Conf-IRA test (Castro, Alves, Correia \& Soares, 2018), being excluded after the assessment period. The children in the same kindergarten that were excluded from the study still attended the classes, but their data was not analyzed in the postassessment. The dropout rate was $16.98 \%$ (9 out of 53 children). The final sample included 44 children ( 25 female) with a mean age of $3 ; 6$ years old. All participants were from two different kindergartens in the same city: Aveiro. The experimental group had weekly music classes, $45 \mathrm{~min} /$ class $(n=23,15$ female, mean age $=3 ; 5$ years old), and the control group ( $n=21,10$ female, mean age $=3 ; 6$ years old) had weekly visual arts classes, $45 \mathrm{~min} /$ class. Children assignment to each class was done randomly, at the beginning of the school year, after the recruitment stage. The children were randomized in Random.org (1st years' timestamp: 2015-10-15 15:31:12 UTC; 2nd years' timestamp: 2016-10-31 16:18:26 UTC). They came from the same demographical region and shared the same socioeconomic background.

\section{Procedures}

Data collection was authorized by the Direção-Geral da Educação (DGE) from Portuguese Ministry of Education and Science (Reference 0504200001, July 28, 2015). Parental informed consent was obtained for each child, and the data was analyzed anonymously. Children were assessed with the phonological awareness test Conf-IRA (Castro et al., 2018) at the beginning and at the end of the school year, before and after the training period. This training period comprises 30 lessons of $45 \mathrm{~min}$ each, each occurring once a week. All children were assessed in individual sessions (in a 30- to 40-min session) at school, in a quiet room, with consent from the parents, the school board, and the teachers. The software SPSS Version 25 and Microsoft Excel 2013 were used for statistical analysis.

\section{Dependent measures}

Pre- and postassessment included phonological awareness skills, assessed with Conf-IRA-Phonological Awareness Screening and Assessment Instrument (Castro et al., 2018). This phonological awareness test comprises 18 tasks evaluating lexical, syllabic, intrasyllabic, and phonemic awareness in words and pseudowords with all syllabic structures existing in EP. Being the most complete test that we know of for EP children at this ages, this was the chosen test to assess our sample. It is being validated and standardized to Portuguese children between 3 and 9 years old. In the present study, taking into account children ages and our specific research goals, 11 tasks were applied, but only 5 are analyzed: syllabification of words (the child sees a picture and listens to a word that (s)he has to segment in syllables, using his/her fingers to divide and count: e.g., the word galo "roaster" must be segmented into "ga" and "lo"); syllabification of pseudowords (the child listens to a pseudoword and has to segment it into syllables using his/her fingers to divide and count: e.g., the pseudoword lofa must be segmented into "lo/fa"); combining syllables into words (the child listens to three syllables separated by a 1-s interval, and at the end (s)he has to put them together, forming an existing word, as in 
$b a_{-} l i \_z a=b a l i z a$ "goal"); combining syllables into pseudowords (the child listens to syllables presented with a 1-s interval, and at the end (s)he has to put them together, creating a nonexisting but possible word: $t u_{-} f a_{-} r o=$ "túfaro"); and rhyme identification (in multiple-choice items with pictures, the child has to choose among three pictures the one that corresponds to the word that rhymes with the name referring to a picture previously presented-in this task metrical rhyme coincides with syllabic rhyme: e.g., pictures of a cat, a spoon, and a dog are presented, referred to in Portuguese by the words gato, colher, or cão, respectively; the child has to select the last one when a picture previously presented corresponds to coração "heart"). Six subtests were removed from our study because they had floor effects for both groups tested, probably being too difficult for all the children in our age group: lexical awareness (segmentation of phrases into words); final syllable omission (the child looks at a picture and listens to a word that turns into a different word when the last syllable is omitted); initial syllable omission (the child sees a picture and listens to a word that turns into a different word when the first syllable is omitted); syllable inversion (the child looks to a picture, listens to a two-syllable word, and changes the order of the syllables to find a different word); first phoneme identification (the child has to identify which of three words does not begin with the same sound as the other two); and last phoneme identification (the child has to identify which of three words does not end with the same sound as the other two).

\section{Design}

Recruitment and data collection happened in two successive school years. After preassessment, children had training classes for a school year. Music and visual arts groups were balanced in number of students. The programs were implemented by trained teachers: each class had two teachers, and the same two teachers were training children in music and visual arts classes. In the first year, both teachers were blind to our research goals. For personal reasons, both professionals had to stop collaborating with this research at the end of the first school year. In the second year, following the first year's methodology, two different trained teachers gave the classes. One of them was blind to our research goals, the second was the first author of this manuscript. Similar to the first year, in the second year the same teachers were engaged in both music and visual arts classes. The four instructors had substantial experience in working with young children. Children in each class (experimental and control groups) were recruited from eight different classes in two kindergartens, and both participating kindergartens had a music and a visual arts group. This procedure aimed to control for the work done by different teachers and to rule out possible kindergarten effects. The children did not receive other music or visual arts lessons during this period. The training programs were matched in duration, themes (e.g., autumn, winter, animals, and Disney) and materials (all materials were used for both classes: autumn leaves, balloons, journal, and rolls of toilet paper, among others).

In the present study, a number of procedures were introduced to control for external variables: (a) kindergarten teachers and parents were blind to the aim of the study in the interest of controlling parental and teachers expectations and possible related changes in their action that might influence children's results; 
Table 1. Means, standard deviations, and frequencies for the control variables of age and gender

\begin{tabular}{|c|c|c|}
\hline & Music group & Visual arts group \\
\hline Control variable & $M(S D)$ & $M(S D)$ \\
\hline Age in months & $41.26(3.53)$ & 42.05 (3.85) \\
\hline Gender & $8 \mathrm{~m} / 15 \mathrm{f}$ & $11 \mathrm{~m} / 10 \mathrm{f}$ \\
\hline
\end{tabular}

(b) only one of the four teachers giving the music and visual arts classes was aware of the research goals, whereas the remaining three were blind to the aim of the study; (c) children had no other forms of music and visual arts classes during the experimental period, making it safe to draw conclusions about the training and its effects on phonological awareness development; and (d) for the evaluation process, and in order to ensure interjudge reliability, $12.24 \%$ of the sample was revised by an external therapist, blind to the purpose of the study. This speech and language therapist also listened to the audiotape of Conf-IRA assessment from six randomly selected children, making the quotation of the tests. Interjudge reliability was analyzed through the percentage of accordance for the total score of Conf-IRA, between two speech therapists and the result was $97.99 \%$.

\section{Control variables}

Differences in gender and age between the music group and the visual art group were compared, as well as the number of children per classroom in each activity class (see Table 1). Male/female ratio was balanced in the visual arts group ( $47.62 \%$ females and $52.38 \%$ males) and also very similar in the music group (65.22\% females and $34.78 \%$ males). The difference in gender distribution in the music group was originated by the randomization process. There were no significant differences between the groups in terms of age $(p>.05)$. See Table 1 for means and standard deviations.

\section{Music lessons}

In the music lessons children were trained for $45 \mathrm{~min}$, once a week, in a quiet room that offered good conditions for the different tasks. A typical session comprised a short welcome (a good morning song or a short talk), a variety of exercises, and a farewell song. The musical work contained activities of listening to and exploring songs from varying genres and styles; joint singing without the lyrics (most of the time); joint drumming; melodic and rhythmic exercises based on musical learning theory (Gordon, 2000); playful familiarization with intervals in occidental music and music using Greek musical modes; improvisation, pitch, intensity, timbre, and rhythmic discrimination exercises; pitch, intensity, timbre and rhythmic production exercises; and moving/dancing along with classical music. Lessons included live instruments or their own voice, familiarization with different instruments, and instrument discrimination exercises, playing with their own body and objects of their day life (e.g., autumn leaves, toys, journals, balloons, and rolls of toilet paper). According to Rodrigues, Rodrigues, Pereira, Rodrigues, and Lopes (2016), using 
chants (melodies without the words) and songs (melodies with the words) is important, but using chants with syllables like pa-pa-pa or lai-lai-lai is crucial, because it makes it easier for the child and the adult to pay attention to the musical aspects, and not to the semantic domain of the vocalizations. Solfege was not part of the music program for these classes.

\section{Visual arts lessons}

In the visual arts lessons, children were also trained for $45 \mathrm{~min}$, once a week, in a quiet room with appropriate conditions for the different tasks. Here, visual arts classes comprehended a great variety of arts, including painting (famous artists and everyday life painting), cinema, architecture, and sculpture. A typical session comprised a short welcome (a good morning movement or statue, or a short talk), a variety of exercises, and a farewell moment. Exercises included the visualization of a small presentation projected on the classroom wall about the life and work of an artist; talks about famous artists, their lives and work, and the colors, shapes, and materials they used; painting and modeling using different materials (e.g., pencils, pens, brushes, hands, gouaches, or pastel pencils; journal with glue, plasticine, or clay); and drawing or constructing with usual and unusual materials (e.g., pencils, glitter, salt, autumn leaves, journals, balloons, or rolls of toilet paper).

\section{Analysis}

A mixed effects analysis of variance was run to look for the influence of training activity and time, or the interaction between them, in our sample. Levene's test was used to look for the homogeneity of variances. Sample normality distribution was inspected in order to determine whether parametric tests ( $t$ test for independent samples) or nonparametric tests (Mann-Whitney test) had to be run when looking for differences between the experimental and the control group in the moments before and after the training period. Taking into account that music training was expected to positively affect phonological awareness development, one-tailed significant values are reported. This analysis refers to Conf-IRA total score, as well to the individual tasks applied: in each task, 1 point is given to the correct answers; total score is the sum of the 5 individual tasks applied. In both cases, data always concern the averages over all participants. For understanding the development inside each group between the pre- and the postassessment, $t$ tests for dependent samples (parametric) or Wilcoxon tests (nonparametric) were applied.

\section{Results}

\section{Phonological awareness results}

Phonological awareness total score

The Conf-IRA results obtained at preassessment in music trained children had a mean score of $5.35(S D=4.30)$ and at postassessment a mean score of 13.43 $(S D=5.03)$. For the visual arts trained children, the Conf-IRA results obtained at preassessment had a mean score of $7.0(S D=3.52)$ and at the postassessment a mean score of $9.71(S D=4.01$; see Figure 2$)$. 


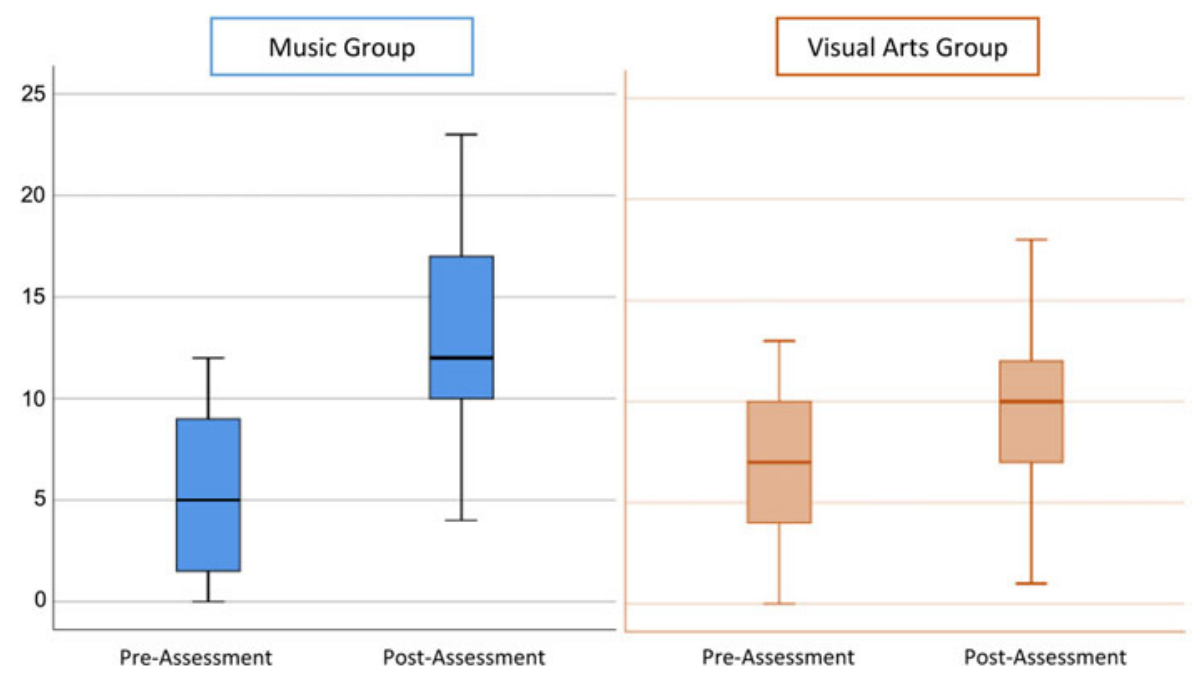

Figure 2. Phonological awareness total scores pre- and postassessment in the music and visual arts groups.

From the analysis of the results of Conf-IRA total score (dependent variable), it is possible to see that the activity by itself (independent variable) had no impact on phonological awareness skills, showing a small effect on the test results, $F(1,42)=1.21, p>.05, r=.17$. However, if we consider the interaction between time and training activity, there were significant differences between groups, $F(1,42)=9.28, p<.01, r=.42$, showing that the type of training activity influenced the development of phonological awareness, with a medium size effect. The homogeneity of variances was tested, showing nonsignificant results in the Levene's test $(p>.05)$. A mixed-effects analysis of variance was conducted to look for possible effects of time and training activity, and the interaction between them.

The results of phonological awareness pre- and postassessment of music and visual arts groups are displayed in Figure 2. As can be seen, the results in the preassessment tests were not significantly different between the groups $(U=298.00, p>.05)$. In the postassessment, by contrast, there were significant differences between them, $t(42)=2.70, p<.01$, with the music group students showing significantly greater improvement in phonological awareness tasks, considering the total scores.

To analyze the data, normality in both groups was tested with the Shapiro-Wilk test, in order to decide between parametric or nonparametric statistical analysis. Given that the music group in the preassessment does not show a normal distribution $(p<.05)$, a nonparametric test (Mann-Whitney) was run for the statistical analysis. In the postassessment both groups showed a normal distribution, given that $p>.05$ at both times, and thus a parametric analysis was run with an independent-samples $t$ test.

Results reveal that the significant interaction that was found between time and training activity happens because music students develop significantly more than visual art students $(p<.05)$ in the assessment done after the training period. As 


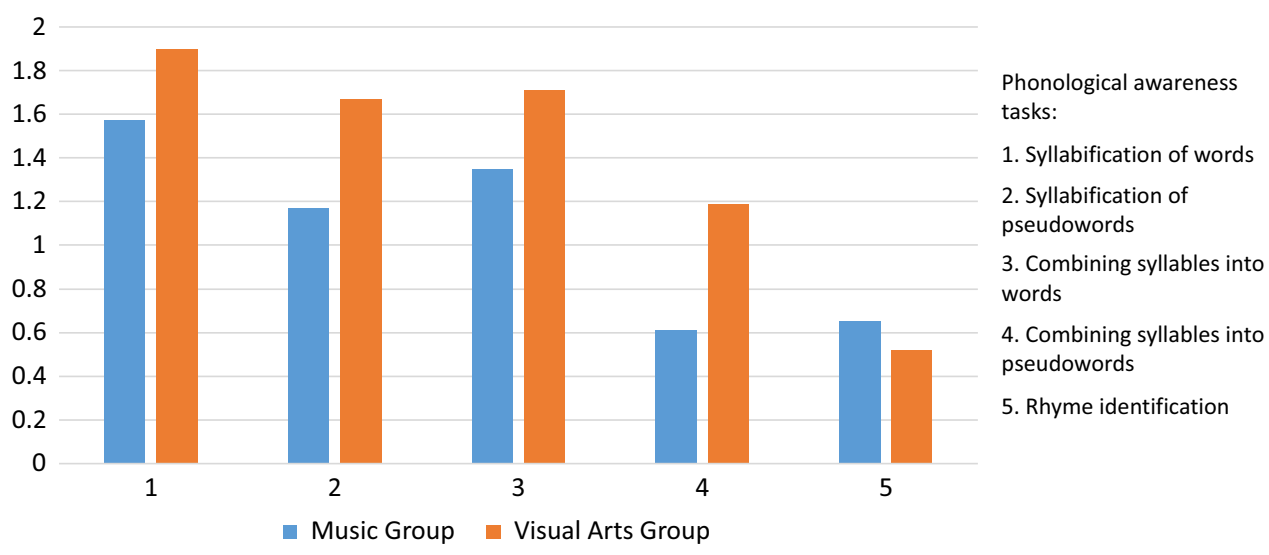

Figure 3. Phonological awareness subtests results at preassessment in the music and visual arts groups.

shown in Figure 2, visual arts students began with a higher result (although the difference was not statistically significant) and also developed their phonological awareness skills, but music students outperformed the children trained in visual arts.

Children trained in music revealed significant differences $(Z=227.00, p<.001)$ between the results before and after the training period, showing great improvement in phonological awareness skills from the preassessment to the postassessment. Preand postassessment results were compared in the experimental group, who had music classes. Normality Shapiro-Wilk tests revealed no normal distribution in pre- and postassessment $(p<.05)$, so a nonparametric analysis was run to seek for differences between the two times: the Wilcoxon test.

In the analysis of the results from the children trained in visual arts, a significant difference was also found, $t(20)=-2.57, p<.05$. Children in this group showed an improvement in phonological awareness from the beginning to the end of the school year (see Figure 2). Normality Shapiro-Wilk tests revealed a normal distribution in pre- and postassessment $(p>.05)$, so a dependent-samples $t$ test was used in order to understand the development between pre- and postassessment in the control group.

\section{Pre- and postassessment comparison: Phonological awareness individual tasks}

Five of the 18 tasks of Conf-IRA were analyzed. When comparing partial scores in the preassessment, there were no significant differences between groups in any task (see Figure 3).

By contrast, significant differences were found between groups in the postassessment, with the group receiving music training showing a significant improvement in the subsequent phonological awareness tasks (see Figure 4): syllabification of words $(U=169.00, p<.05)$ and pseudowords $(U=130.00$, $p<.01)$; combining syllables into words $(U=154.00, p<.05)$ and pseudowords $(U=162.00, p<.05)$. Rhyme identification (task 5$)$ revealed an inversion in the direction of the results expected, as visual arts students showed better results in 


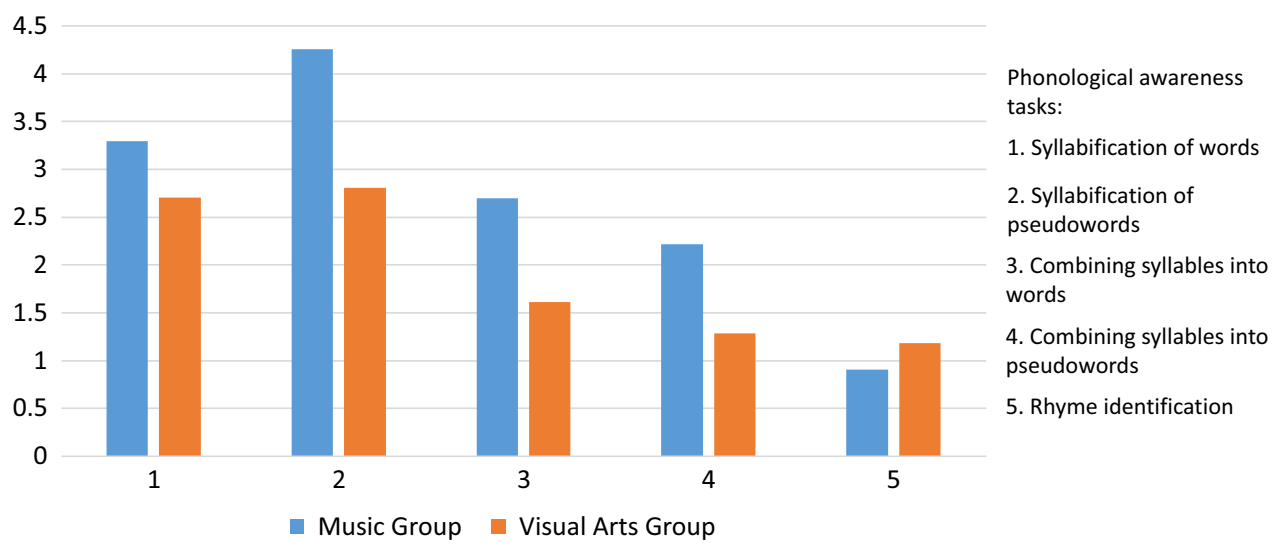

Figure 4. Phonological awareness subtests results at postassessment in the music and visual arts groups.

these tasks, but the difference between the two groups was not significant $(U=278.00, p>.05)$. Shapiro-Wilk normality tests $(p<.05)$ led us to analyze the data with nonparametric statistical analyses, with a Mann-Whitney test for independent samples.

\section{Discussion}

The aim of this study was to investigate the effect of a school year of weekly music classes in phonological awareness skills of 3-year-old children, prior to the ages studied so far in EP, or in other languages (see online-only Supplemental Material Table S.2). A systematic phonological awareness assessment was made considering a variety of tasks that is not frequently seen in other studies. The results indicate that the music classes, with the intensity delivered (one lesson of $45 \mathrm{~min}$ per week, during 30 weeks), led to a greater development of phonological awareness skills, when compared with the visual arts training (subject to intensity of lessons). In this study there were no intensive classes, with the purpose of seeking for music and language relations in typical classes, following a methodology that is achievable in everyday kindergarten routines. We also did not work phonological awareness explicitly, even removing the words, lyrics, and rhymes of the songs used in classes.

\section{Phonological awareness total score}

Looking at pre- and postassessment results, we can see that both groups significantly developed phonological awareness skills (music group $p<.001$; visual arts group $p<.05)$. However, music students outperformed visual arts students in the postassessment, and there was a significant difference between both groups in the posttraining assessment. These results are in line with Anvari et al. (2002), who concluded that 4- and 5-year-olds' music perception ability is related to phonological awareness skills (including phonological and phonemic levels), as well as with Lathroum (2011), who showed that music perception predicts phonological 
awareness development in 5- and 6-year-old children. Woodruff Carr et al. (2014) also found that beat-synchronization is correlated with prereading skills in 3- and 4-year-olds (which includes, among others, phonological awareness skills), and Degé et al. (2015) found associations between music production and phonological awareness skills in 4-year-olds. Degé and Schwarzer (2012) found in addition significant positive associations between the total score of phonological awareness test and the overall scores of music perception and production.

With a test-training-retest methodology, using a control group with a nonrelated training, we can assume that music was the reason for the larger development of phonological awareness skills found. This indicates that there is a possible causal relation between music and phonological awareness development. These results corroborate Patscheke et al. (2016), who found significant differences between children with music and phonological awareness training (1st and 2nd experimental groups), and the control group that was exposed to sports training, with music trained children showing a larger effect size in the phonological awareness results. In their meta-analysis study, Gordon et al. (2015) also concluded that music training has a positive effect on phonological awareness development above the age of 4 . Bolduc (2009) found significant differences between the experimental group and the control group in phonological awareness skills as well, but here the experimental group followed a specific program that joined music and phonological awareness stimuli, whereas the control group followed a music program only. Although we did not design a specific program to develop phonological awareness skills among with music, we found significant differences in phonological awareness development. The findings of our study suggest that regular music classes positively influence language development (specifically phonological awareness), even when using a methodology that is not focused specifically in linguistic work.

\section{Phonological awareness partial scores}

Our partial results on the phonological awareness tasks indicate significant differences at the level of phonological units larger than the segment: syllabification of words $(p<.05)$, syllabification of pseudowords $(p<.01)$, combining syllables into words $(p<.05)$, and combining syllables into pseudowords $(p<.05)$. These analyses are purely exploratory, and $p$ values should be interpreted carefully.

Music trained children when compared to visual arts students had significantly higher scores in syllabification of words and pseudowords. This is in line with the data in Moritz (2007), who compared syllable segmentation (among other phonological awareness skills) and rhythmic skills in kindergartners, and in Herrera et al. (2011), who studied the influence of a phonological awareness program and a music program in syllabic tapping (mean age $=4 ; 6$ ), and who concluded that children with musical training in both experimental groups outperformed the control group, with no musical training. However, in these studies it was impossible to exclude the effect of extra-attention in the experimental groups. In the present study, by contrast, the only factor that seems to have played a role in the large significant difference in word and pseudoword segmentation tasks was the fact that children were exposed to training lessons specifically in music. 
Significant differences in combining syllables into words and pseudowords were also found in our study. This reveals that music students developed better abilities to analyze and manipulate language at the syllable level. According to Lathroum (2011), blending seems to have a strong rhythmic component, and this may be one of the reasons for the influence found.

No significant results were obtained in rhyme identification in the experimental group. This may seem surprising because it goes against what was found by Herrera et al. (2011), for 4- to 6-year-old children. In contrast, in the meta-analysis study developed by Gordon et al. (2015), it was shown that rhyme skills results tended to grow stronger with increased hours of training, an observation also reported in Moritz (2007). This leads us to hypothesize that with an intensive training or longer period of intervention, it could be possible to have differences between both groups. Other methodological differences may also explain the discrepancies between our results and those in the literature cited. An indication that this may be the case is the fact that our results are similar to those reported in another study that followed a method largely similar to ours, namely, Moreno et al. (2011). In this study, no significant differences on rhyming assessment were found either, and, although employing an intensive training methodology, using a computerized program and using musical staff like note to sound mapping, different from what we did in our study, the music training program was similar to the one we used, including training of rhythm, melody, pitch, and voice. The authors do not report, however, if they use the lyrics of the songs, which in our case did not in general happened. This fact can also influence our results, and may indicate that together with the structural rhythmic, melodic, and harmonic music constituents, the semantic part of the songs has an important effect on rhyming ability.

\section{Conclusion}

The results of this study support the hypothesis that music has an effect on the development of phonological (syllabic) awareness in toddlerhood, as early as 3 years of age.

Our results show significant differences in the development of large phonological units awareness in music students when compared to visual arts students: music trained children had greater development in word segmentation into syllables, pseudowords segmentation into syllables, syllabic synthesis of words, and syllabic synthesis of pseudowords.

In the total score of the Conf-IRA test, it is possible to see that all students developed between the pre- and the postassessment, but music students showed significantly greater improvement than the control group, subject to visual arts lessons.

The present study has some methodological limitations that should be acknowledged. First, children's motivation was not measured. This could be important to ensure that there was no difference between the experimental and control groups in this respect (Degé \& Schwarzer, 2011; Patscheke et al., 2016); however, no dropout happened because of demotivation, suggesting that all children in both groups were equally motivated. Second, the first author was one of the teachers conducting the training in the second year, being aware of the aim of the study and the training type received 
(Moreno et al., 2011). Under these conditions, teaching can be unconsciously biased, even when, as in this case, the ethical principles of objectivity, rigor, and honesty were respected as much as possible (Bolduc, 2009). The elimination of outliers and the exclusion of some subtests might be also considered a limitation.

Some of the studies reviewed in this paper are music-based interventions specifically designed to promote specific reading skills, and some have an intensive periodicity that would be difficult to implement in our schools and daily lives. In the present study, the effect of music on phonological awareness development was proved to happen after regular music classes, with lessons that are likely to be applied by common music teachers in a kindergarten context. This observation has potential implications for the state policies regarding kindergarten education curricula, as this may be an effective and simple way to promote better academic achievements.

This study showed that music promotes phonological awareness at a very early stage in the development of several phonological awareness skills. As it is known that these skills are relevant for the learning of writing and reading (Anthony \& Francis, 2005; Gordon et al., 2015; Wright \& Jacobs, 2003), our results suggest that generalized music lessons in kindergarten might positively contribute to the learning of writing and reading in the first school years.

Acknowledgments. This research was partially supported by the Portuguese Foundation for Science and Technology (Grants SFRH/BD/98841/2013 and UID/LIN/00214/2019) in conjunction with the European Regional Development Fund (ERDF) from the EU, Portugal 2020, and Lisboa 2020 (Grant PTDC/LLT-LIN/ 29338/2017), as well as by ERDF COMPETE2020 (Grant POCI-01-0145-FEDER-007746) and the Portuguese Foundation for Science and Technology (Grant UID/IC/4255/2019). The authors would like to gratefully acknowledge all the children and childhood educators who participated in this study, Jardim de Infância do Centro Social e Paroquial da Vera Cruz, Jardim de Infância de Santiago, the music and visual arts teachers Ausenda Dias, Laura Santos, and Mariana Miguel, and Marisa Cruz for her help in the statistical analyses. We would also like to thank Sónia Frota, whose comments were crucial from the beginning to the end.

Supplementary material. To view supplementary material for this article, please visit https://doi.org/10. 1017/S0142716419000535

\section{References}

Afonso, C. M. de C. (2015). Complexidade Prosódica-Tarefas de consciência fonológica em crianças do $1^{\circ}$ Ciclo do Ensino Básico (Unpuplished manuscript, Universidade de Lisboa). Retrieved from http:// repositorio.ul.pt/bitstream/10451/23966/1/ulsd072798_td_Catarina_Afonso.pdf

Alves, D., Castro, A., \& Correia, S. (2009). Consciência Fonológica-Dados sobre consciência fonémica, intrassilábica e silábica. In Associação Portuguesa de Linguística (Ed.), Textos Seleccionados do XXV Encontro da Associação Portuguesa de Linguística (pp. 169-184). Porto, Portugal, October 21-23.

Anthony, J. L., \& Francis, D. J. (2005). Development of phonological awareness. Current Directions in Psychological Science, 14, 255-259. doi: 10.1111/j.0963-7214.2005.00376.x

Anvari, S. H., Trainor, L. J., Woodside, J., \& Levy, B. A. (2002). Relations among musical skills, phonological processing, and early reading ability in preschool children. Journal of Experimental Child Psychology, 83, 111-130. doi: 10.1016/S0022-0965(02)00124-8

Bion, R. A. H., Benavides-Varela, S., \& Nespor, M. (2011). Acoustic markers of prominence influence infants' and adults' segmentation of speech sequences. Language and Speech, 54, 123-140. doi: 10. $1177 / 0023830910388018$

Bishop, D. V. M., \& Snowling, M. J. (2004). Developmental Dyslexia and Specific Language Impairment: same or different? Psychological Bulletin, 130, 858-886. doi: 10.1037/0033-2909.130.6.858 
Bolduc, J. (2009). Effects of a music programme on kindergartners' phonological awareness skills 1. International Journal of Music Education, 27, 37-47. doi: 10.1177/0255761408099063

Butzlaff, R. (2000). Can music be used to teach reading? Journal of Aesthetic Education, 344, 167-178. doi: $10.2307 / 3333642$

Cardoso-Martins, C. (1991). Awareness of phonemes and alphabetic literacy acquisition. British Journal of Educational Psychology, 61, 164-173. doi: 10.1111/j.2044-8279.1991.tb00972.x

Castro, A., Alves, D., Correia, S., \& Soares, C. (2018). Phonological Awareness Screening and Assessment Tool for European Portuguese Speaking Children (p. 1). Paper presetned at the 10th European Congress of Speech and Language Therapy, Cascais, Potugal, May 10-12.

Catts, H. W., Adlof, S. M., Hogan, T. P., \& Weismer, S. E. (2005). Are specific language impairment and dyslexia distinct disorders? Journal of Speech, Language, and Hearing Research, 48, 1378-1396. doi: 10. 1044/1092-4388(2005/096)

Clegg, J., Hollis, C., Mawhood, L., \& Rutter, M. (2005). Developmental language disorders-a follow-up in later adult life. Cognitive, language and psychosocial outcomes Journal of Child Psychology and Psychiatry, and Allied Disciplines, 46, 128-149. doi: 10.1111/j.1469-7610.2004.00342.x

Collischonn, G., \& Wetzels, W. L. (2016). Syllable structure. In W. L. Wetzels, S. Menuzzi, \& J. Costa (Eds.), The handbook of Portuguese linguistics (pp. 86-106). Malden, MA: Wiley.

Corrigall, K. A., \& Trainor, L. J. (2011). Associations between length of music training and reading skills in children music perception. Music Perception, 29, 147-155. doi: 10.1525/mp.2011.29.2.147

Degé, F., Kubicek, C., \& Schwarzer, G. (2015). Associations between musical abilities and precursors of reading in preschool aged children. Frontiers in Psychology, 6, 1-10. doi: 10.3389/fpsyg.2015.01220

Degé, F., \& Schwarzer, G. (2011). The effect of a music program on phonological awareness in preschoolers. Frontiers in Psychology, 2, 1-7. doi: 10.3389/fpsyg.2011.00124

Degé, F., \& Schwarzer, G. (2012). Investigating the associations between musical abilities and precursors of literacy in preschool children. Proceedings of the 12th International Conference on Music Perception and Cognition (ICMPC) and 8th Triennial Conference of the European Society for the Cognitive Sciences of Music (ESCOM), 250-251.

Forgeard, A. M., Schlaug, G., Rosam, C., Iyengar, U., \& Winner, E. (2008). The relation between music and phonological processing in normal- reading children and children with dyslexia. Music Perception: An Interdisciplinary Journal, 25, 383-390.

François, C., Chobert, J., Besson, M., \& Schön, D. (2013). Music training for the development of speech segmentation. Cerebral Cortex, 23, 2038-2043. doi: 10.1093/cercor/bhs180

Freitas, M. J., Alves, D., \& Costa, T. (2007). O conhecimento da língua: Desenvolver a consciência fonológica. Lisboa: Ministério da Educação. Retrieved from http://scholar.google.com/scholar?hl=en\&btnG= Search\&q=intitle:O+Conhecimento $+\mathrm{da}+\mathrm{L}$ ?ngua $+:+$ Desenvolver $+\mathrm{a}+$ consci?ncia + fonol?gica\# 0

Frota, S. (2000). Prosody and focus in European Portuguese. Phonological phrasing and intonation. New York: Garland Publishing.

Frota, S. (2014). The intonational phonology of European Portuguese. In S.-A. Jun (Ed.), Prosodic typology II (pp. 6-42). Oxford: Oxford University Press.

Frota, S., Cruz, M., Matos, N., \& Vigário, M. (2016). Early prosodic development. Emerging intonation and phrasing in European Portuguese. In M. Armstrong, N. C. Henriksen, \& M. M. Vanrell (Eds.), Intonational grammar in Ibero-Romance: approaches across linguistic subfields (pp. 295-324). Amsterdam: Benjamins.

Gerry, D., Unrau, A., \& Trainor, L. J. (2012). Active music classes in infancy enhance musical, communicative and social development. Developmental Science, 15, 398-407. doi: 10.1111/j.1467-7687.2012.01142.x

Gordon, E. (2000). Teoria da Aprendizagem Musical: Competênci Assessment and Instruction. Boston: Allyn \& Bacon.

Gordon, R. L., Fehd, H. M., \& McCandliss, B. D. (2015). Does music training enhance literacy skills? A meta-analysis. Frontiers in Psychology, 6. doi: 10.3389/fpsyg.2015.01777

Goswami, U. (1990). A Special link between rhyming skill and the use of orthographic analogies by beginning readers. Journal of Child Psychology and Psychiatry, 31, 301-311. doi: 10.1111/j.1469-7610.1990. tb01568.x

Gromko, J. E. (2005). The effect of music instruction on phonemic awareness in beginning readers. Journal of Research in Music Education, 53, 199. doi: 10.2307/3598679 
Herrera, L., Lorenzo, O., Defior, S., Fernandez-Smith, G., \& Costa-Giomi, E. (2011). Effects of phonological and musical training on the reading readiness of native- and foreign-Spanish-speaking children. Psychology of Music, 39, 68-81. doi: 10.1177/0305735610361995

Krumhansl, C. (2000). Rhythm and pitch in music cognition. Psychological Bulletin, 126, 159-179.

Lamb, S. J., \& Gregory, A. H. (1993). The relationship between music and reading in beginning readers. Educational Psychology, 13, 19-27. doi: 10.1080/0144341930130103

Lane, H. B., \& Pullen, P. C. (2004). A sound beggining: phonological awareness assessment and instruction. Boston: Allyn \& Bacon.

Lathroum, L. (2011). The role of music perception in predicting phonological awareness in five-and six-yearold children (Unpublished doctoral dissertation, University of Miami).

Lehrdahl, F., \& Jackendoff, R. (1983). An overview of hierarchical structure in music. Music Perception, 1, 229-252.

Lyon, G. R. (1998). The NICHD research program in reading development, reading disorders, and reading instruction: a summary of research findings. Keys to successful learning: A national summit on research in learning disabilities. New York: The National Center for Learning Disabilities.

Mateus, M. H. M., \& D'Andrade, E. (2000). The phonology of Portuguese. Oxford: Oxford University Press.

McMullen, E., \& Saffran, J. R. (2004). Music and language: A developmental comparison. Music Perception, 21, 289-311. doi: 10.1525/mp.2004.21.3.289

Moreno, S., Friesen, D., \& Bialystok, E. (2011). Effect of music training on promoting preliteracy skills: Preliminary causal evidence. Music Perception, 29, 165-172. doi: 10.1525/mp.2011.29.2.165

Moreno, S., Marques, C., Santos, A., Santos, M., Castro, S. L., \& Besson, M. (2009). Musical training influences linguistic abilities in 8-year-old children: More evidence for brain plasticity. Cerebral Cortex, 19, 712-723. doi: 10.1093/cercor/bhn120

Moritz, C. E. (2007). Relationships between phonological awareness and musical rhythm subskills in kindergarten children and comparison of subskills in two schools with different amounts of music instruction. TUFTS University.

Öney, B., \& Durgunoğlu, A. Y. (1997). Beginning to read in Turkish: A phonologically transparent orthography. Applied Psycholinguistics, 18, 1. doi: 10.1017/S014271640000984X

Overy, K. (2003). Dyslexia and music: From timing deficits to musical intervention. Annals of the New York Academy of Sciences, 999, 497-505. doi: 10.1196/annals.1284.060

Patel, A. D. (2003). Language, music, syntax and the brain. Nature Neuroscience, 6, 674-681. doi: 10.1038/ nn1082

Patel, A. D. (2008). Music, language and the brain. Oxford: Oxford University Press.

Patel, A. D. (2011). Why would musical training benefit the neural encoding of speech? The OPERA hypothesis. Frontiers in Psychology, 2, 1-14. doi: 10.3389/fpsyg.2011.00142

Patscheke, H., Degé, F., \& Schwarzer, G. (2016). The effects of training in music and phonological skills on phonological awareness in 4- to 6-year-old children of immigrant families. Frontiers in Psychology, 7, 1-13. doi: 10.3389/fpsyg.2016.01647

Peynircioglu, Z. F., Durgunoglu, A. Y., \& Uney-Kusefoglu, B. (2002). Phonological awareness and musical aptitude. Journal of Research in Reading, 25, 68-80. doi: 10.1111/1467-9817.00159

Radocy, R. E., LeBlanc, A., \& Boyle, J. D. (1990). Psychological foundations of musical behavior (4th ed.). Springfield, IL: Thomas.

Rios, A. C. (2009). Competências fonológicas na transição do pré-escolar para o 1.ociclo do ensino básico (Unpublished manuscript, Universidade de Aveiro).

Rodrigues, H., Rodrigues, P. F., Pereira, A. I., Rodrigues, A., \& Lopes, F. (2016). Manual para a Construção de Jardins Interiores-Colos de Música. Lisboa: Fundação Calouste Gulbenkian.

Rubinson, L. E. (2009). A correlational study of the relationships between music aptitude and phonemic awareness of kindergarten children. Capella University.

Saffran, J. R., Johnson, E. K., Aslin, R. N., \& Newport, E. L. (1999). Statistical learning of tone sequences by human infants and adults. Cognition, 70, 27-52. doi: 10.1016/S0010-0277(98)00075-4

Santos, A. R. (2012). Consciência fonológica em crianças de idade pré-escolar (Unpublished manuscript, Universidade de Aveiro).

Schlaggar, B. L., \& McCandliss, B. D. (2007). Development of neural systems for reading. Annual Review of Neuroscience, 30, 475-503. doi: 10.1146/annurev.neuro.28.061604.135645

Sim-Sim, I. (2006). Ler e Ensinar a Ler. Lisboa: ASA Editores. 
Wagner, R. K., Torgesen, J. K., Rashotte, C. A., Hecht, S. A., Barker, T. A., Burgess, S. R., ... Garon, T. (1997). Changing relations between phonological processing abilities and word-level reading as children develop from beginning to skilled readers: A 5-year longitudinal study. Developmental Psychology, 33, 468-479. doi: 10.1037/0012-1649.33.3.468

Woodruff Carr, K., White-Schwoch, T., Tierney, A. T., Strait, D. L., \& Kraus, N. (2014). Beat synchronization predicts neural speech encoding and reading readiness in preschoolers. Proceedings of the National Academy of Sciences, 111, 14559-14564. doi: 10.1073/pnas.1406219111

Wright, J., \& Jacobs, B. (2003). Teaching phonological awareness and metacognitive strategies to children with reading difficulties: A comparison of two instructional methods. Educational Psychology, 23, 17-47. doi: $10.1080 / 01443410303217$

Yopp, H. K. (1992). Developing phonemic awareness in young children. Reading Teacher, 45, 696-703. doi: $10.2307 / 20200960$

Zuk, J., Andrade, P. E., Andrade, O. V. C. A., Gardiner, M., \& Gaab, N. (2013). Musical, language, and reading abilities in early Portuguese readers. Frontiers in Psychology, 4, 1-12. doi: 10.3389/fpsyg.2013. 00288

Cite this article: Vidal, M.M., Lousada, M., and Vigário, M. (2020). Music effects on phonological awareness development in 3-year-old children. Applied Psycholinguistics 41, 299-318. https://doi.org/10.1017/ S0142716419000535 